\title{
The effect of R\&D-based innovations on value adding
}

\begin{abstract}
R\&D-based innovations have important roles in value adding in an enterprise. Maintaining and/or increasing certain levels of innovation can be possible with a continuous innovation program in the company. At first glance, improving value-add seems to be an issue that can be analyzed at the micro level. Actually, improving it is the first link in the chain that ends with a national innovation system. Therefore, innovation must be taken into account for all value-add studies and evaluated on a global level.
\end{abstract}

This model was designed to measure the model enterprise's innovation activities by using innovation index values and innovation data published by different institutions. The model was applied to a model textile firm that is active in Turkey. The value found from the model was compared with Turkey's innovation index value. Thus, the firm's innovation performance was measured in an objective way.

The model can be used for measuring or comparing innovation performance and developing future strategies for companies, institutions and regions.

Keywords: innovation, R\&D, value-add, innovation systems, measuring innovation
Volume 2 Issue 2 - 2017

\author{
Asli Girgin, Yusuf Ulcay \\ Uludag University, Turkey
}

Correspondence: Asli Girgin, Uludag University, Selvili Caddesi, Savas Apt. Kat: 2 No: 30 Cekirge Osmangazi Bursa, Turkey Tel 90533432 I62I, Email asli-girgin@hotmail.com

Received:May 26, 2017| Published: June 19, 2017
Abbreviations: GII, global innovation Index; IPM, innovation performance measurement; BSC, balanced scorecard; EFQM, european foundation for quality management; WIPO, world intellectual property organization; EIS, european innovation scoreboard

\section{Introduction}

Since innovation is a dynamic and partly-controlled process, measuring it is a challenge, thus there is no standardized and generally accepted method for this process. This is an alternative and practical model for building up an innovation map in a cluster or region.

Different types of measurement methods and different approaches are needed for each lever of innovation systems. Innovation systems each have special requirements and different approaches; their measurement systems could be "hybrids" of each other, but they should not be the same. The aim of this research is to find an alternative approach for measuring innovation at the micro lever and to develop these hybrid measurement methods. Finding practical and generally accepted models for determining an enterprise's innovation lever, makes it possible to have more strategic and clearer innovation plans in a firm. The aim of this study is to find a convenient model to measure innovation in an enterprise using data from global innovation measurement methods. The global innovation index (GII) was chosen for this purpose, as it has detailed indicators. As the textile sector is a traditional sector, there are only a limited number of researches available on innovation. Thus, more research is needed in this area.

Numerous definitions of innovation have been proposed in the literature. One common definitions of innovation is "the successful exploitation of new ideas". ${ }^{1}$ Innovation could be defined as a process of knowledge production, involving a degree of uncertain results. Innovation is defined as all types of innovations including products, services, processes, technologies, and business models.
To make innovation sustainable within the enterprise, it is important to have a well-defined innovation performance measurement (IPM) system. The performance of a commercial enterprise can be measured by financial methods and operational efficiency methods. The traditional financial performance measures worked well for the industrial era, but they are not suitable for modern innovation measuring techniques in an enterprise. ${ }^{2}$ For that reason, operational efficiency was chosen as a measurement method in this study.

Many IPM systems were designed. These include the performance measurement matrix Keegan et $\mathrm{al}^{3}{ }^{3}$ the results and determinants framework Fitzgerald et al ${ }^{4}$ the performance pyramid, ${ }^{5}$ the balanced scorecard (BSC), ${ }^{2}$ and the performance prism Neely et al ${ }^{6}$ Performance prism has five criteria for innovation measurements. These are stakeholder satisfaction, strategies, processes, capabilities, and stakeholder contributions. The European Foundation for Quality Management (EFQM) is a good model for understanding causeeffect relationships in an organization. Its indicators are leadership, strategies, people, partnerships and resources, processes, products and services.

A balanced scorecard has a very important place in IPM systems, as many studies were based on the balanced scorecard model. According to the Balanced Scorecard Institute, "the balanced scorecard is a strategic planning and management system that is used extensively in business and industry, government, and nonprofit organizations worldwide to align business activities to the vision and strategy of the organization, improve internal and external communications, and monitor organization performance against strategic goals". ${ }^{8}$

The balanced scorecard for R\&D and innovation was accepted and recommended in many studies including ${ }^{8-11}$ accepted the balanced scorecard, and they have recommended three additional dimensions: strategic measurements, technology management measurements and knowledge management measurements. 
Lazzarotti et al. ${ }^{12}$ have used a model for measuring R\&D performance based on the four perspectives of the balanced scorecard. The indicators of performance in this model are categorized into three categories: $R \& D$ input, $R \& D$ process and $R \& D$ output.

There were other studies separate from the balanced scorecard..$^{13}$ Presented a scheme comprised of 10 disparate dimensions for managing and measuring innovation. The indicators were leadership, resourcing innovations, systems and tools, offering innovations, offering developments, technology transfers, technology acquisitions, market focus, innovation performance and networking.

A lifecycle-oriented approach was recommended. ${ }^{14}$ Milbergs and Vonortas (2005) have classified innovation measures across four generations (input measures, output measures, innovation measures and process measures). There were six key perspectives (inputs, knowledge management, innovation strategy, organization and culture, portfolio management, project management and commercialization) in the innovation measurement model recommended by Adams et al. ${ }^{15}$ Ojanen $\mathrm{V}^{16}$ have listed out five broad methods in their study; these were based on measurement perspective, purpose of measurement, measurement level, R\&D type and process phase, providing a visual tool to help enterprises categorize and select the optimal R\&D measures.

Relevant literature was examined to determine innovation model indicators. An innovation measurement scheme should be multi-dimensional; it should contain awell-balanced combination of financial and non-financial measures. It should also contain past and future probable performance indicators. ${ }^{2} \mathrm{R} \& \mathrm{D}$ activities affected the individual enterprise's effort for innovation. The R\&D efforts of the individual enterprise can positively affect its capacity to produce new and superior products. ${ }^{17}$ Research has shown a strong correlation between R\&D intensity and indicators of innovation output. ${ }^{18}$ Investments in R\&D should not be expected to have significant shortterm beneficial effect on innovation. The research shows that the relationship that develops with sources increases the performance of companies. ${ }^{19}$ The sources of knowledge could be market, institutions and others such as fairs, conferences and industrial associations. Interaction with these sources can provide missing external inputs into the learning process, which the enterprise itself cannot entirely provide..$^{20}$ A firm's innovation capacity is reflected in many factors such as the knowledge of employees, management method, culture, internal and external relationship networks, R\&D expenditure, and number of patents. ${ }^{21}$

There are many new methodologies and techniques that aim to measure the innovation performance of countries. One of the most detailed works has been implemented by the OECD. The first manual that contains the definition and measurement of innovation was developed by a mutual study realized by the OECD and the European Commission. Oslo Manuael addresses standards for defining and measuring innovation. Many countries accepted these standards, and while adopting the fundamental principles underlined in the manual, they developed their own surveys for enterprises within their geographical boundaries. There are many other institutions, such as the World Bank, INSEAD, Economist Intelligence Unit, and Fraunhofer Research Institute that periodically implement similarly structured innovation surveys and performance measurement systems. ${ }^{22}$

In this study, the data were obtained from Global Innovation Index (GII) 2013 published by the Cornell University, INSEAD, and
World Intellectual Property Organization (WIPO). ${ }^{23}$ The GII relies on two sub-indices: the Innovation Input Sub-Index and the Innovation Output Sub-Index. The Innovation Input Sub-Index includes five input pillars, which capture elements of the national economy that enable innovative activities: institutions, human capital and research, infrastructure, market sophistication, and business sophistication. The Innovation Output Sub-Index outlines that innovation outputs are the results of innovative activities within the economy. There are two output pillars: knowledge and technology outputs and creative outputs. The overall GII score is the simple average of the Input and Output Sub-Indices. Each pillar is divided into three sub-pillars, and each sub-pillar is composed of individual indicators for a total of 84 indicators. The GII 2013 model includes 142 economies, representing $94.9 \%$ of the world's population and $98.7 \%$ of the world's GDP (in current US dollars) (GII 2013). The other data source for this research is the European Innovation Scoreboard (EIS). The EIS provides an annual assessment of innovation performance across the EU and with other innovative nations. The EIS is based on a wide range of indicators including structural conditions, knowledge creation, and innovative efforts by firms, and outputs in terms of new products, services and intellectual property. ${ }^{24}$

Hypotheses include the following and are based on the literature. The amount of researchers per million people is not positively related to the innovation index. The business and university collaboration on $R \& D$ is not positively related to the innovation index. The gross expenditure on R\&D is not positively related to the innovation index; the high-tech net imports (\% of total net imports) is not positively related to the innovation index; the number of scientific and technical journal articles (per billion PPP\$ GDP) is not positively related to the innovation index; the high-tech net exports is not positively related to the innovation index; the high-tech and medium-high-tech outputs (\% of total manufactures output) is not positively related to the innovation index; the number of patent applications filed by residents at the national patent office (per billion PPP\$ GDP) is not positively related to the innovation index; the current expenditure on education (\% of GNI) and joint ventures/strategic alliances (number of deals, fractional counting per trillion PPP dollar GDP) is not positively related to the innovation index.

The aim of this study is to examine if a convenient model to measure innovation in an enterprise could be found using global innovation measurement method data, considering that micro and macro data are closely connected. This study explores the possibility of using a global innovation measurement method, which has been modified for effective use by enterprises, to measure country-specific innovation performance. For that purpose, data were taken from the Global Innovation Index (GII) and EIS, hypotheses were tested, and a model was built. The data were taken from one of the textile enterprises and applied to the model.

\section{Methods}

In this study, the data sources are the GII 2013 and EIS 2013. Since innovation is a very complex process, it was not possible to analyze all the indicators in this study. Nine indicators were chosen as independent variables that were considered to be the most important according to the literature. The innovation index was a dependent variable. Independent variables were researchers per million people, business and university collaboration (it is quantified as the average answer to the survey question: To what extent do business 
and universities collaborate on R\&D in your country? 1=Do not collaborate at all; $7=$ Collaborate extensively), gross expenditure on $R \& D$, high-tech net imports ( $\%$ of total net imports), number of scientific and technical journal articles (per billion PPP\$ GDP), high-tech net exports ( $\%$ of total net exports), high-tech and mediumhigh-tech output ( $\%$ of total manufactures output), number of patent applications filed by residents at the national patent office (per billion PPP\$ GDP), current expenditure on education (\% of GNI) and joint ventures/strategic alliances (number of deals, fractional counting; per trillion PPP dollar GDP).

Other data were taken from one of the textile companies in Turkey. These data were applied to the model. Data taken from the textile company were the number of weaving machines, number of employees, number of employees for R\&D, production ( $\mathrm{kg} / \mathrm{person} /$ hour), labor costs for an hour, total labor costs, productivity, R\&D cost, export ratio in total sales, high technology goods in total production. Data were collected for a 10-year period (2002-2011).

Regression analysis was conducted for hypothesis testing in this research. Both linear and nonlinear regression analyses were completed.

Dependent variables were defined as follows:

$\mathrm{x}_{1}$ : Researchers per million people

$\mathrm{x}_{2}$ : Business and university collaboration on $\mathrm{R} \& \mathrm{D}$

$\mathrm{x}_{3}$ : Gross expenditure on $\mathrm{R} \& \mathrm{D}$

$\mathrm{x}_{4}$ : Number of scientific and technical journal articles

$\mathrm{x}_{5}$ : High-tech net exports

$\mathrm{x}_{6}$ : High-tech and medium-high-tech output

$\mathrm{x}_{7}$ : Number of patent applications filed by residents at the national patent office

$\mathrm{x}_{8}$ : Current expenditure on education

$\mathrm{x}_{9}$ : Joint ventures/strategic alliances: Number of deals, fractional counting

$\mathrm{x}_{10}$ : Communications, computer and information services exports

The linear regression analysis model is

$$
\mathrm{y}=\mathrm{b}_{0}+\mathrm{b}_{1} \mathrm{x}_{1}+\mathrm{b}_{2} \mathrm{x}_{2}+\mathrm{b}_{3} \mathrm{x}_{3}+\mathrm{b}_{4} \mathrm{x}_{4}+\mathrm{b}_{5} \mathrm{x}_{5}+\mathrm{b}_{6} \mathrm{x}_{6}+\mathrm{b}_{7} \mathrm{x}_{7}+\mathrm{b}_{8} \mathrm{x}_{8}+\mathrm{b}_{9} \mathrm{x}_{9}
$$

There are nine hypotheses for this model. Hypotheses were built and examined to determine if an independent variable was related to the innovation index (dependent variable). For example, the first hypothesis was that "Researchers per million people are not related to the innovation index" The second was that "Business and university collaboration on R\&D is not related to the innovation index" Each hypothesis was built as follows.

The nonlinear regression analysis model is

$\mathrm{y}=\mathrm{a}+\mathrm{bx}_{1}+\mathrm{cx}_{2}+\mathrm{dx}_{3}+\mathrm{ex}_{4}+\mathrm{fx}_{5}+\mathrm{gx}_{6}+\mathrm{hx}_{7}+\mathrm{ix}_{8}+\mathrm{kx}_{10}+\mathrm{lx}_{1}^{2}+\mathrm{mx}_{2}^{2+}$ $\mathrm{nx}_{3}^{2}+\mathrm{ox}_{4}^{2}+\mathrm{px}_{5}^{2}+\mathrm{qx}_{6}^{2}+\mathrm{rx}_{7}^{2}+\mathrm{sx}_{8}^{2}+\mathrm{tx}_{10}{ }^{2}+\mathrm{ux}_{1} \mathrm{x}_{2}+\mathrm{vx}_{1} \mathrm{x}_{3}+\mathrm{y}_{1} \mathrm{x}_{1} \mathrm{x}_{4}$ $+\mathrm{zx}_{1} \mathrm{x}_{5}+\mathrm{a}_{1} \mathrm{x}_{1} \mathrm{x}_{6}+\mathrm{b}_{1} \mathrm{x}_{1} \mathrm{x}_{7}+\mathrm{c}_{1} \mathrm{x}_{1} \mathrm{x}_{8}+\mathrm{d}_{1} \mathrm{x}_{1} \mathrm{x}_{10}+\mathrm{e}_{1} \mathrm{x}_{2} \mathrm{x}_{3}+\mathrm{f}_{1} \mathrm{x}_{2} \mathrm{x}_{4}+\mathrm{g}_{1} \mathrm{x}_{2} \mathrm{x}_{5}$ $+\mathrm{h}_{1} \mathrm{x}_{2} \mathrm{x}_{6}+\mathrm{i}_{1} \mathrm{x}_{2} \mathrm{x}_{7}+\mathrm{j}_{1} \mathrm{x}_{2} \mathrm{x}_{8}+\mathrm{k}_{1} \mathrm{x}_{2} \mathrm{x}_{10}+\mathrm{1}_{1} \mathrm{x}_{3} \mathrm{x}_{4}+\mathrm{m}_{1} \mathrm{x}_{3} \mathrm{x}_{5}+\mathrm{n}_{1} \mathrm{x}_{3} \mathrm{x}_{6}+\mathrm{o}_{1} \mathrm{x}_{3} \mathrm{x}_{7}$

$+\mathrm{p}_{1} \mathrm{x}_{3} \mathrm{x}_{8}+\mathrm{q}_{1} \mathrm{x}_{3} \mathrm{x}_{10}+\mathrm{r}_{1} \mathrm{x}_{4} \mathrm{x}_{5}+\mathrm{s}_{1} \mathrm{x}_{4} \mathrm{x}_{6}+\mathrm{t}_{1} \mathrm{x}_{4} \mathrm{x}_{7}+\mathrm{v}_{1} \mathrm{x}_{4} \mathrm{x}_{8}+\mathrm{y}_{2} \mathrm{x}_{4} \mathrm{x}_{10}+\mathrm{z}_{1} \mathrm{x}_{5} \mathrm{x}_{6}$

$+\mathrm{a}_{2} \mathrm{x}_{5} \mathrm{x}_{7}+\mathrm{b}_{2} \mathrm{x}_{5} \mathrm{x}_{8}+\mathrm{c}_{2} \mathrm{x}_{5} \mathrm{x}_{10}+\mathrm{d}_{2} \mathrm{x}_{6} \mathrm{x}_{7}+\mathrm{e}_{2} \mathrm{x}_{6} \mathrm{x}_{8}+\mathrm{f}_{2} \mathrm{x}_{6} \mathrm{x}_{10}+\mathrm{g}_{2} \mathrm{x}_{7} \mathrm{x}_{8}+\mathrm{h}_{2} \mathrm{x}_{7} \mathrm{x}_{10}$ $+\mathrm{i}_{2} \mathrm{x}_{8} \mathrm{x}_{10}$
There were 109 hypotheses for this model: nine for single variables and 100 for other variables. For single variables, hypotheses were built (similar to the linear model). The other hypothesis, which contains binary interactions, were built as follows: "Researchers per million people and business and university collaborations on R\&D interaction is not related to the innovation index". Every binary interaction was similar.

\section{Results}

Linear and nonlinear regression analyses were performed. For the nonlinear model, from the ANOVA analysis in Table 1, it's proved that innovation index is related with dependent variables. For the nonlinear model, the $\mathrm{R}^{2}$ value was 0.985 , so the model was accepted: the interaction between the number of patent applications filed by residents at the national patent office and the current expenditure on education was related to the innovation index, the interaction between the number of patent applications filed by residents at the national patent office and gross expenditure on $R \& D$ was related to the innovation index (coef $=-2.6197, \mathrm{q}=0.019)$, the interaction between the number of patent applications filed by residents at the national patent office and communications, computer and information services exports was related to the innovation index ( $\operatorname{coef}=0.2334, \mathrm{q}=0.02$ ), the interaction between the current expenditure on education and business and universities collaboration on R\&D was related to the innovation index (coef $=-1.4758, \mathrm{q}=0.02$ ), the interaction between the number of patent applications filed by residents at the national patent office, and the number of scientific and technical journal articles was related to the innovation index (coef $=0.0709, \mathrm{q}=0.054)$. For this model, other variables and interaction were not related to the innovation index.

Another nonlinear model was also built. In this model, all the square variables were ignored. For the nonlinear model in which the square variables were ignored, the $\mathrm{R}^{2}$ value was 0.980 , so the model was accepted. For this model, it was found that the interaction between the number of patent applications filed by residents at the national patent office and the current expenditure on education was related to the innovation index (coef $=-0.3088, q=0.021)$, the interaction between the number of patent applications filed by residents at the national patent office and the number of researchers per million people was related to the innovation index $(\operatorname{coef}=0.0005, \mathrm{q}=0.055)$, the interaction between business and university collaboration on R\&D and current expenditure on education was related to the innovation index (coef $=-0,9615, q=0.032)$, and the interaction between high-tech net exports and high-tech and medium-high-tech output (\% of total manufactures output) was related to the innovation index (coef $=$ $0.0183, \mathrm{q}=0.05$ ). For this model, other variables and interaction were not related to the innovation index.

A linear model, which uses the independent variables of the EIS, was also proposed. From the ANOVA analysis in Table 2, it's proved that innovation index is related with dependent variables. For this linear model $\left(\mathrm{R}^{2}=0.888\right)$, which was accepted, we found that business and university collaboration on R\&D was related to the innovation index and that the number of patent applications filed by residents at the national patent office was related to the innovation index.

For the linear model whose independent variable used the GII data, from the ANOVA analysis in Table 3, it's proved that innovation index is related with dependent variables. From linear regression analysis, we found that the number of researchers per million people was related to the innovation index, business and university collaboration 
on R\&D was related to the innovation index, number of scientific and technical journal articles was related to the innovation index, and high-tech net exports was related to the innovation index.

The linear model and nonlinear models both explained the innovation index. It is preferred to use the linear model because of its practicality and simple structure. Data were taken from a textile enterprise in Turkey. Data were collected for ten years (2003-2012). The average value was $\$ 7.5$ dollars per one kilogram of textile material. The total production of the enterprise in 2012 was $55545 \mathrm{~kg}$. The total sales in 2012 was \$4 165905 dollars. The number of researchers per 50000 employees was 2200 (There were 6 researchers for 136 employees). Business and university collaborate on R\&D was accepted as " 1 " in the scale (This is scale 1 to 7 ; No collaboration between universities and business means " 1 "). The enterprise's expenditure on R\&D for a ten year period was 416.032dollar (the enterprise's expenditure on R\&D was $\$ 332062$ in 2003, the firm's expenditure on R\&D was $\$ 61070$ in 2006, the enterprise's expenditure on R\&D was \$22 900 in 2010). Enterprise's expenditure on R\&D (\% of total sales) in 2012 was $\% 0.998$. The number of technical journals that the firm published was zero. The firm's high-tech net export was $20 \%$. The enterprise's high-tech and medium-high-tech output ( $\%$ of total manufactures output) was $10 \%$. The enterprise's number of patent applications was 0.0962 (The firm had four patents applications for ten years). Expenditure on education in 2012 was $\$ 10$ 700. The firm's expenditure on education (of total sales) was $0,26 \%$. Joint ventures/ strategic alliances (Number of deals, fractional counting) was zero. There were no strategic alliances. When these values applied for the model, it was found that $36,67.25,26$

Table I Analysis of Variance for Nonlinear Regression

\begin{tabular}{lllllll}
\hline \multicolumn{6}{l}{ Analysis of variance for $\boldsymbol{y}$} \\
\hline Source & DF & Seq SS & Adj SS & Adj MS & F & P \\
\hline Regression & 54 & 8217.21 & 8217.211 & 152.1706 & 13.17 & 0 \\
Linear & 9 & 7413.74 & 210.606 & 23.4007 & 2.03 & 0.088 \\
Square & 9 & 292.29 & 90.267 & 10.0297 & 0.87 & 0.567 \\
Interaction & 36 & 511.18 & 511.183 & 14.1995 & 1.23 & 0.313 \\
Residual Error & 21 & 242.64 & 242.637 & 11.5541 & & \\
Total & 75 & 8459.85 & & & & \\
\hline
\end{tabular}

Table 2 Analysis of Variance for Linear Regression ( $y$ is the EIS values)

\begin{tabular}{|c|c|c|c|c|c|}
\hline \multicolumn{6}{|c|}{ ANOVA } \\
\hline Model & Sum of squares & Df & Mean square & $\mathbf{F}$ & Q \\
\hline Regression & 0.91 & 9 & 0.1 & 20.269 & 0 \\
\hline Residual & 0.12 & 23 & 0.01 & & \\
\hline Total & 1.03 & 32 & & & \\
\hline
\end{tabular}

Table 3 Analysis of Variance for Linear Regression (y is Gll values)

\begin{tabular}{|c|c|c|c|c|c|}
\hline \multicolumn{6}{|c|}{ ANOVA } \\
\hline Model & Sum of squares & Df & Mean square & $\mathbf{F}$ & Q \\
\hline Regression & 7365.76 & 9 & 818.418 & 49.37 & 0 \\
\hline Residual & 1094.089 & 66 & 16.577 & & \\
\hline Total & 8459.849 & 75 & & & \\
\hline
\end{tabular}

\section{Discussion and conclusion}

The Global Innovation Index which was the source of this study has 84 indicators to measure the innovation index. The number of indicators was too many for this type of study, and many of these indicators could not be applied to an enterprise. The indicators were chosen based on how important they were and how successfully they applied to an enterprise. In light of this, nine variables were chosen according to prior studies. The aim was to develop a useful and practical model to measure innovation in a firm. A linear model was preferred for its practicality and ease of use.

The number of researchers per 50,000 employees was 2,200 in the enterprise. Researchers per million people in Turkey were 1,715.35 in 2013. The enterprise's value was higher than Turkey's value (GII 2013) (rank 41). The enterprise's business and university collaboration on R\&D was " 1 ". Business and university collaboration on R\&D in Turkey in 2013 was 3,9(Rank 69). The firm's expenditure on R\&D (\% of total sales) in 2012 was one. Gross expenditures on R\&D in Turkey in 2013 were 0.84.(Rank 38). The number of technical journals that the firm published was zero. The number of scientific and technical journal articles (per billion PPP\$ GDP) in Turkey in 2013 was 20.86 (Percent rank 0.68). The enterprise's high-tech net exports were $20 \%$. Turkey's high-tech net exports in 2013 were $8 \%$. The enterprise's high-tech and medium-high-tech output (\% of total manufactures output) was $10 \%$. Turkey's high-tech and mediumhigh-tech output (\% of total manufactures output) in 2013 was 
26.5\% (Rank 37). The enterprise's number of patent applications was 0.0962 .The number of patent applications filed by residents at the national patent office (per billion PPP\$ GDP) in Turkey in 2013 was 3.2(Rank 46). The enterprise's expenditure on education (\% of total sales) was $0.26 \%$.Tukey's current expenditure on education ( $\%$ of GNI) was 2.6 (Rank 101). The enterprise's innovation index value $(36,67)$ was nearly same as Turkey's innovation index value (36.06). As the enterprise could represent Turkey, it was an expected result. As the firm produces medium technology products, the innovation lever is a low-medium lever, thus, the model is successful. Using a hypothetical high innovation lever firm value can test the models an imaginary innovation lever enterprise. The number of researchers per 50000 employees was 10000 in the firm (the researcher number is 20 and the total employee number is 100).The R\&D value for business and university collaboration is 5. Enterprise's expenditure on R\&D (\% of total sales) is $3 \%$. (There is a current business and university collaboration at a high level in the enterprise that consists of three projects in the university). The number of technical journals that the enterprise published for 1000 employee was 10 (the enterprise publishes one technical journal monthly). The firm's high-tech net exports were $50 \%$. When these values were applied to the model, the innovation index was 66.61. This value is nearly same as Switzerland's innovation value (66.59) (GII 2013).

The model is not a stable one; it is open for further expansion. Indicators could also be changed. With this model, enterprises in a cluster or in a region can be classified by the innovation lever. Enterprises can also measure their innovation lever to know their strong and weak points. By knowing every enterprise's innovation lever in a region or country, governments can make clearer strategic policies, and institutions can help enterprises gain dynamic competitive advantages. Institutional and regional innovation levers can also be measured. The innovation index value can be used similar to other commercial indicators as an enterprise's profile. It would be advantageous for a country such as Turkey, which does not have enough innovation culture.

\section{Acknowledgments}

None.

\section{Conflict of interest}

Author declares there is no conflict of interest in publishing the article.

\section{References}

1. Branson R. An Audience with Innovation: Innovation in Management Department of Trade and Industry London, UK; 1998.

2. Kaplan RS, Norton DP. The Balanced Scorecard-Measures That Drove Performance. Harvard Bus Rev. 1992;70(1):71-79.

3. Keegan DP, Eiler RG, Jones CR. Are Your Performance Measures Obsolete? Manage Acc. 1989;70(12):45-50.

4. Fitzgerald L, Johnston R, Brignall TJ, et al. Performance Measurement in Service Business. London: CIMA Publishing; 1991;69(10):34.
5. Lynch RL, Cross KF. Measure Up-The Essential Guide to Measuring Business Performance. Mandarin, London, UK; 1991.

6. Neely A, Adams C, Kennerley M. The Performance Prism: The Scorecard for Measurement and Managing Business Success. Financial Times Prentice Hall. 2002.

7. Balanced Scorecard Basices. 2015.

8. Wong A. The Metrics of Innovation. Virtual Strategist. 2001;1:1-5.

9. Bremser WG, Barsky NL. Utilizing the balanced scorecard for R\&D performance measurement. R\&D Manage. 2004;34(3):229-238.

10. Gama N, Da Silva MM, Ataide J. Innovation Scorecard: a balanced scorecard for measuring value added by innovation. In: Cunha PF, Maropoulos PG, editors. Digital Enterprise Technology. USA: Springer; 2007. p. $417-424$.

11. Chiesa V, Frattini F. An exploratory study on R\&D performance measurement practices- a survey of Italian R\&D-intensive firms. Int J Innovation Manage. 2009;13(1):65-104.

12. Lazzarotti V, Manzini R, Mari L. A model for R\&D based performance measurement. Int J Prod Econ. 2011;134(1):212-223.

13. Verhaeghe A, Kfir R. Managing innovation in a knowledge intensive technology organization. R\&D Manage. 2002;32(5):409-417.

14. Suomala P. The life cycle dimension of new product development performance measurement. Int J Innov Manage. 2004;8(2):193-221.

15. Adams R, Bessant J, Pheelps R. Innovation management measurement: A review. Int J Manage Rev. 2006;8(1):21-47.

16. Ojanen V, Vuola O. Coping with the multiple dimensions of R\&D performance analysis. Int J Technol Manage. 2006;33(2):279-290.

17. Cohen W, Levinthal D. Absorptive capacity: Anew perspective on learning and innovation. Administrative Science Quarterly. 1990;35(1):128-52.

18. Kamien MI, Schwarz NL. Market structure and innovation. Cambridge: Cambridge University Press; 1982.

19. Hausman A, Stock JR. Adaptation and implementation of technological innovations within long-term relationships. $J$ Business Research. 2003;56(8):681-686.

20. Rominj H, Albaladejo M. Determinant of innovation capability in a small electronics software firms in southeast England. Research Policy. 2002;31(7):1053-1067.

21. Feeny S, Rogers M. Innovation and performance: Benchmarking Australian firms. The Australian Economic Review. 2003;36(3):253-264.

22. Karaata ES. New Seeking in the Measurement of Innovation. TUSIAD, Turkey: Sabanci University Press; 2012.

23. INSEAD. The Global Innovation Index 2013: The Local Dynamics of Innovation. Cornell University, Geneva, Switzerland; 2013. p. 1-417.

24. European Commission. Innovation Union Scoreboard 2013. Belgium; 2013. p. 1-80.

25. Helfat CE. Firm specificity in corporate applied R \& D. Organization Science. 1994;5(2):173-184.

26. Denyer D, Neely A. Introduction to special issue; Innovation and productivity performance in the UK. International J Management Review. 2004;5-6(3-4):131-135. 